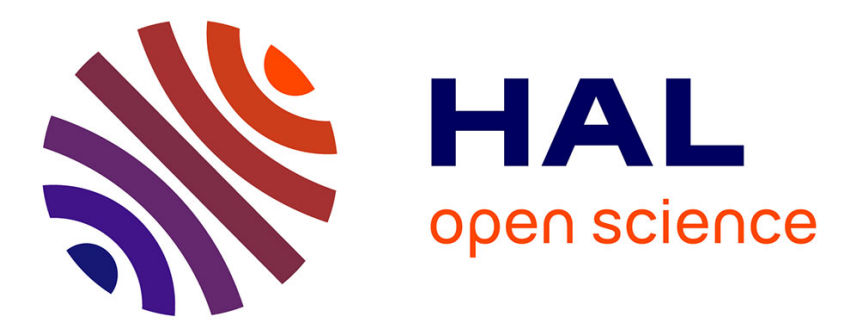

\title{
Reliability characteristics of thin porous low-K silica-based interconnect dielectrics
}

\author{
Yohan Barbarin, K. Croes, P. Roussel, Y. Li, L. Zhao, P. Verdonck, M.
} Baklanov, Z. Tokei

\section{- To cite this version:}

Yohan Barbarin, K. Croes, P. Roussel, Y. Li, L. Zhao, et al.. Reliability characteristics of thin porous low-K silica-based interconnect dielectrics. 2013 IEEE International Reliability Physics Symposium (IRPS), Apr 2013, Monterey, United States. pp.2F.3.1-2F.3.5, 10.1109/IRPS.2013.6531968 . hal02549212

\section{HAL Id: hal-02549212 \\ https://hal.science/hal-02549212}

Submitted on 21 Apr 2020

HAL is a multi-disciplinary open access archive for the deposit and dissemination of scientific research documents, whether they are published or not. The documents may come from teaching and research institutions in France or abroad, or from public or private research centers.
L'archive ouverte pluridisciplinaire HAL, est destinée au dépôt et à la diffusion de documents scientifiques de niveau recherche, publiés ou non, émanant des établissements d'enseignement et de recherche français ou étrangers, des laboratoires publics ou privés. 


\title{
Reliability Characteristics Of Thin Porous Low- $K$ Silica-Based Interconnect Dielectrics
}

\author{
Y. Barbarin, K. Croes, P. Roussel, Y. Li, L. Zhao, P. Verdonck, M. Baklanov and Zs. Tökei \\ Imec, Kapeldreef 75, B-3001 Leuven, Belgium \\ yohan.barbarin@gmail.com
}

\begin{abstract}
The time-dependent-dielectric-breakdown of eight different low- $K$ films with porosities between $3 \%$ and $50 \%$ and thicknesses between 15 and $120 \mathrm{~nm}$ were investigated using imec planar capacitors. The analogous OSG-films show all power-law field acceleration factors of $\mathbf{- 2 1}$ independently of porosity. Weibull slopes decrease linearly with thickness and porosity. The maximum allowed electrical fields to meet 10 -years lifetime are discussed and data show that for 20-nm spacing remedial measures are required for porosities $>\mathbf{3 0} \%$.
\end{abstract}

Keywords: TDDB, Porous low-K, Reliability, Lifetime model.

\section{INTRODUCTION}

Time dependent dielectric breakdown (TDDB) became one of the most critical reliability issues for $C u /$ low- $K$ interconnect systems [1] as k-values and dielectrics spaces decrease. In this paper we discuss the reliability predictions as a function of $K$ value down to 1.8 and thickness down to $15-20 \mathrm{~nm}$. The studied porosity range is between $3 \%$ and $50 \%$. To carefully study these phenomena, TDDB studies using damascene structures are not fully suitable because the results can be affected by the different processing steps: low- $k$ patterning damage, $C u$ chemical mechanical polishing (CMP) residues, line-edge-roughness (LER) and CD variations [2]. In the current work, imec's planar capacitor test structure $[3,4]$ was used to access intrinsic properties. In section II, the electrical field acceleration factors of the different low- $K$ 's is studied. The porosity and the dielectric thickness have no impacts on field enhancement factors parameters [5]. However, the porosity as well as the dielectric thickness have an impact on the lifetime because the Weibull slope is affected. The reduction of the Weibull slope as a function of the porosity was described with the percolation model $[5,6]$. The reduction of the Weibull slopes as a function of dielectric thickness was reported for thin gate oxide [7] and high-k materials [8]. These two reductions of the Weibull slopes were evaluated in section III using an extended model. A valuable parameter to compare $C u /$ metal-barrier/low- $k$ structures is the maximum allowed electrical field to meet 10 years lifetime at a given percentile such as $0.01 \%$. $\mathrm{E}_{\mathrm{MAX}}$ is by definition strongly affected by lower Weibull slope values. In Section IV, $\mathrm{E}_{\mathrm{MAX}}$ values of the different low- $K$ 's and different thicknesses are discussed.

\section{LOW-K ELECTRICAL FIELD ACCELERATION FACTORS}

We investigated the TDDB properties of 6 different OSG films with thicknesses between 15 and $120 \mathrm{~nm}$ and $K$-values of $3.2,3.0,2.5,2.3(\mathrm{~A}) \&(\mathrm{~B}), 2.0$ (A) with porosities of respectively $3,7,25,29$ and 45\%. A 2.0(B) OSG film sealed with a protecting layer of $12-\mathrm{nm}$ OSG 3.0 was also included into the evaluation. Additionally, a 45-nm thick periodic mesoporous organosilica (PMO) film with a $K$-value of 1.8 and a porosity of $50 \%$ was also evaluated with the same 12-nm OSG 3.0 sealing cap. The planar capacitor test structure described in $[3,4]$ was used. This planar capacitor design enables intrinsic TDDB study of barrier/low- $K$ systems. The low- $K$ films are deposited into areas of typically $100 \times 100 \mu \mathrm{m}^{2}$. For these experiments TaN-based $\mathrm{Cu}$-barriers were used.

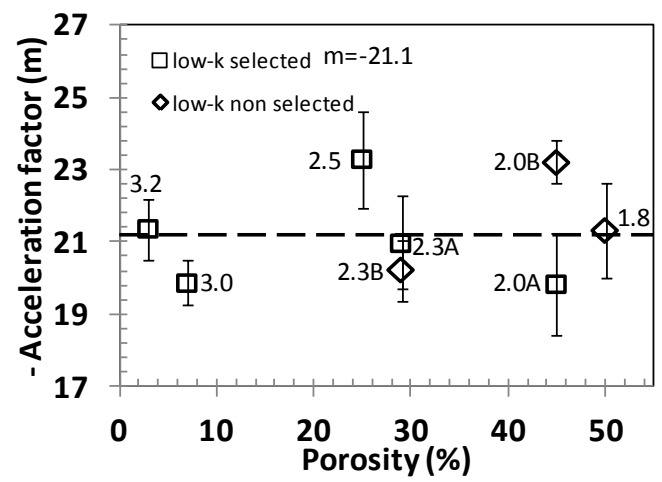

Figure 1. Power law electrical field acceleration factor $(\mathrm{m})$ measured at $100^{\circ} \mathrm{C}$ as a fucntion of porosity for different low- $K$ materials.

All TDDB data measured at $100^{\circ} \mathrm{C}$ were fitted using the power law model (TTF $\left.\sim \mathrm{V}^{\mathrm{m}}\right)$ which according to [9] fits TDDB data in a more realistic way than for instance the $E$-model. Note that the conclusions made in the paper do not depend on the chosen lifetime model. For each material listed above, the fittings were performed simultaneously using maximum likelihood estimation for all thicknesses assuming the same acceleration factor and different Weibull slopes. All resulting electrical field acceleration factors (m) are plotted in fig. 1 as a function of porosity. Comparing those numbers and analyzing as well the Weibull slopes, we found that the 3.2, 3.0, 2.5, 2.3(A), and 2.0(A) OSG films can be compared directly. The acceleration factors are on the same level as the percolation model predicts $[5,6]$. The averaged $m$-value for those selected low- $K$ 's is -21 . The material compositions might be close enough regardless of the porosity. The sealed OSG 2.0(B) and PMO 1.8 films have also acceleration factors very close to -21 .

\section{LOW-K POROSITY AND THICKNESS INFLUENCE ON WEIBULL SLOPES}

The pores in thin low- $K$ films have a major impact on the breakdown electrical field [5] and time-to-failure through the Weibull slope $(\beta)$. We predict the Weibull slope as a function of porosity and dielectric thickness as expressed in Eq.1 based 
on $[5,6]$. The factor $(1+\alpha) \cdot P$ represents the additional defective sites of the pores, $\mathrm{P}$ is the porosity and $\alpha$ a field enhancement factor [6]. Like observed in [7], we assume a linear decrease of the Weibull slope with thickness, adding the component $\delta \cdot\left(d_{\max }-d\right) . \beta_{0, d \max }$ is the Weibull slope obtained for a nonporous dielectric for a given maximum thickness which is $60 \mathrm{~nm}$ in the present work.

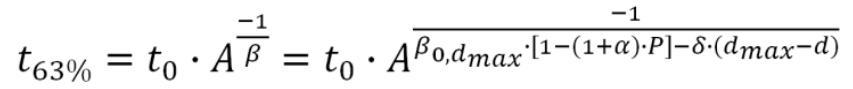

$\beta$-values for thicknesses of 20, 40 and $60 \mathrm{~nm}$ are plotted in Fig. 2 as a function of low- $K$ porosity. Note the high $\beta$-values of the OSG-2.3(B) film with $29 \%$ porosity for the 3 thicknesses. The reason is currently under investigation and could eventually be linked to a higher leakage. Also note the high $\beta$-values of the sealed films, which are the OSG-2.0(B) with $45 \%$ porosity ( 35 and $15-\mathrm{nm}$ thick) and the PMO-1.8 with $50 \%$ porosity ( $45-\mathrm{nm}$ thick). These high $\beta$ 's are obviously linked to the sealing. All the other data points corresponding to the $3.2,3.0,2.5,2.3(\mathrm{~A})$, and $2.0(\mathrm{~A})$ low- $K$ 's were fitted together using the model of $\beta$ in Eq. 1. The resulting extrapolations are the three dashed lines in Fig. 3 for 60,40 and $20 \mathrm{~nm}$. The data points are all very close to the model in this thickness range. We obtained $\beta_{0,60 \mathrm{~nm}}=5.6, \alpha=0.49$ and $\delta=8.4 \mathrm{E}+5 \mathrm{~cm}^{-1}$. The Weibull slope dependence on the low- $K$ porosity and thickness shown in Fig. 2 leads to critical lifetime limitations in $C u /$ low- $K$ interconnect systems. This graph predicts that the maximum porosity suitable for 20-nm spacing is $<30 \%$ and that the minimum spacing for $50 \%$ low- $K$ porosity is $>50 \mathrm{~nm}$. In the following section the impact on the lifetime is discussed.

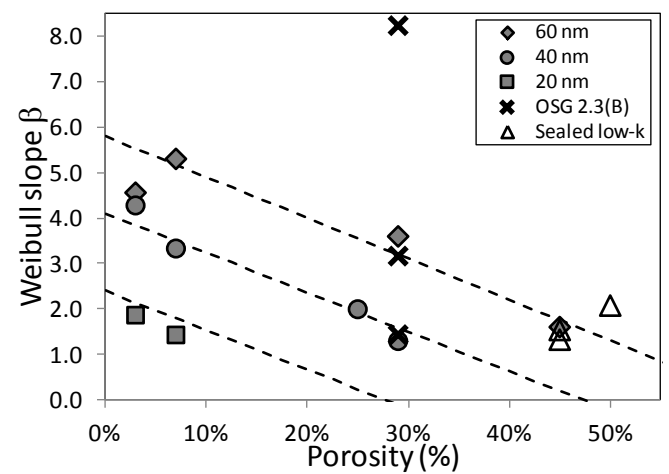

Figure 2. Weibull slopes' values for thicknesses of 20,40 and $60 \mathrm{~nm}$ as a function of low- $K$ porosity. The dashed lines show the fits for the 3 thicknesses. Only the data with filled markers were used in the fit.

\section{POROSITY AND THICKNESS INFLUENCE ON EMAX}

The decrease of the Weibull slope with increasing porosity and reduced low- $K$ thicknesses limits the expected lifetime at a given percentile. We define $\mathrm{E}_{\mathrm{MAX}}$ as the maximum allowed electrical field to meet 10 years lifetime at a percentile of $0.01 \%$. $\mathrm{E}_{\mathrm{MAX}}$ values, for all low- $K$ 's described in section I, are plotted as a function of thickness in Fig.3.a and as a function of porosity for 20, 40 and $60 \mathrm{~nm}$ films in Fig.3.b. For the comparable OSG films fitted in section III, $\mathrm{E}_{\mathrm{MAX}}$ decreases directly with $\beta$ thus with thickness and higher porosity. At 60-nm spacing, $\mathrm{E}_{\mathrm{MAX}}$ decreases from $3.1 \mathrm{MV} / \mathrm{cm}$ for $\mathrm{k}=3.2$ down to $1.6 \mathrm{MV} / \mathrm{cm}$ for $\mathrm{k}=2.0$ without any sealing. At $20-\mathrm{nm}$ spacing, $\mathrm{E}_{\mathrm{MAX}}$ for the OSG-3.2 film is reduced to $2.7 \mathrm{MV} / \mathrm{cm}$. At this spacing, an $\mathrm{E}_{\mathrm{MAX}}$ value of $1.7 \mathrm{MV} / \mathrm{cm}$ was measured for the OSG-2.3(B) low- $K$, but this film showed really higher $\beta$ values in section III. For the OSG-2.5 film, it couldn't be measured directly at this thickness, but it can be predicted using the bulk breakdown electrical field, the averaged m-value measured in section II and the Weibull slopes calculated in section IV. We predict an $\mathrm{E}_{\mathrm{MAX}}$ value of only $0.35 \mathrm{MV} / \mathrm{cm}$ for 20-nm OSG-2.5, which is really below $\mathrm{Cu} /$ low- $\mathrm{K}$ interconnect specifications. In Fig 3.a and b, it is interesting to look at the sealed 2.0(B) and 1.8 low- $K$ 's, they perform as well as the 2.0(A) and 2.3(B) films, however their integration in sub-20nm interconnects is a major milestone.
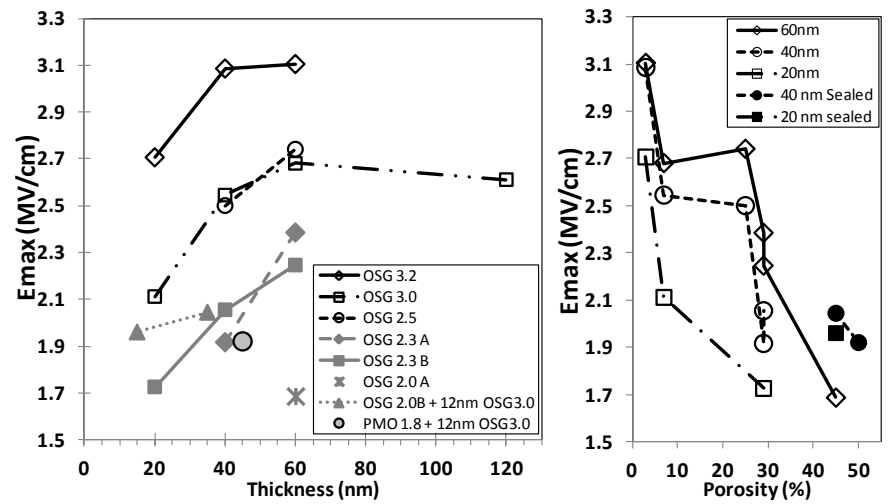

Figure 3. a) $\mathrm{E}_{\mathrm{MAX}}$ as a function of thickness for different low- $K$ 's and $b$ ) $\mathrm{E}_{\mathrm{MAX}}$ as a function of low- $K$ 's porosity for 20,40 and $60 \mathrm{~nm}$ films.

\section{CONCLUSION}

In this paper we could experimentally show that many analogous low- $K$ 's with porosity between 3 and $45 \%$ have the same field acceleration factor $(\mathrm{m}=-21)$. The predicted lifetime is linked to the Weibull slope. We experimentally showed the Weibull slope is inversely proportional to porosity and proportional to low-k thickness. This is in agreement with the percolation model. In 20-nm $\mathrm{Cu} /$ low- $K$ interconnects, severe reliability issues rise for low- $K$ porosities higher than $30 \%$. Sealing very porous low- $K$, such as the PMO 1.8 presented in this work, allowed to increase the Weibull slope and thus $\mathrm{E}_{\max }$. However this approach introduces a bi-layer dielectric system, which needs to be further investigated, especially to predict lifetime at operating conditions.

\section{REFERENCES}

[1] Zs. Tökei et al., J. Microelectron. Eng. 87(3), p.384, (2009)

[2] K. Croes et al., Proc. IRPS, p.142, (2011)

[3] L. Zhao et al., Proc. IRPS, p.848, (2009)

[4] L. Zhao et al., J. Appl. Phys. 99, 222110, (2011)

[5] E.T. Ogawa et al., Proc. IRPS, p.166, (2003)

[6] S.C. Lee et al., Proc. IRPS, p.481, (2009)

[7] E.Y. Wu et al., IEEE T-ED, Vol. 49., No 2, p.2141 (2002)

[8] T. Kauerauf et al. IEEE EDL, Vol. 23, No. 4, p. 215 (2002)

[9] K. Croes et al., subimtted to IRPS (2013) 